\title{
Corticosterone pretreatment suppresses stress-induced hypothalamic-pituitary-adrenal axis activity via multiple actions that vary with time, site of action, and de novo protein synthesis
}

\author{
Chad Osterlund and Robert L Spencer \\ Department of Psychology and Neuroscience, University of Colorado, UCB 345, Boulder, Colorado 80309, USA \\ (Correspondence should be addressed to C Osterlund; Email: chad.osterlund@colorado.edu)
}

\begin{abstract}
Glucocorticoid regulation of the hypothalamic-pituitaryadrenal (HPA) axis is believed to depend on multiple actions operative within discrete time domains. However, the underlying cellular and molecular mechanisms for those glucocorticoid actions remain undetermined. Moreover, there is absence of in vivo studies examining whether there are multiple glucocorticoid effects on HPA axis-related function within an intermediate feedback time frame $(1-3 \mathrm{~h}$ after glucocorticoid elevation), and whether those effects depend on de novo protein synthesis. We examined in rats the effects of protein synthesis inhibition on HPA axis response to restraint $(15 \mathrm{~min})$ after 1 and $3 \mathrm{~h}$ phasic corticosterone (CORT) pretreatment. We measured HPA axis hormones (ACTH and CORT) and gene expression in the paraventricular nucleus (c-fos and $c r h$ genes), as well as gene expression in the anterior and intermediate pituitaries (c-fos and pomc
\end{abstract}

genes). Both CORT pretreatment intervals produced inhibition of stress-induced ACTH secretion, but no inhibition was observed in the presence of protein synthesis inhibition. CORT pretreatment produced inhibitory effects on stress-induced gene expression that varied for each gene depending on the anatomical site, pretreatment time, and protein synthesis dependency. Taken together, the ACTH and gene expression patterns support the presence of multiple independent glucocorticoid actions initiated during the intermediate glucocorticoid negative feedback phase. Moreover, we conclude that those effects are exerted predominantly on the intrinsic anatomical elements of the HPA axis, and some of those effects depend on CORT induction of the expression of one or more regulatory gene products.

Journal of Endocrinology (2011) 208, 311-322

\section{Introduction}

Based largely on a number of innovative in vitro and in vivo studies conducted in the 1960's and 1970's, the existence and importance of glucocorticoid negative feedback control of the hypothalamic-pituitary-adrenal (HPA) axis became established. Most of those studies relied on indirect measures of hormone levels, and the in vivo studies were typically conducted under non-physiological conditions (e.g. animals were anesthetized or adrenalectomized). A model of glucocorticoid negative feedback function emerged from those studies that featured the hypothesis that glucocorticoids exert multiple cellular effects that vary in their time course and anatomical site of action. Dallman \& Yates (1969) were the first researchers to provide clear demonstration that negative feedback actions of glucocorticoids operate in temporally distinct phases. This emerging model of glucocorticoid negative feedback function was presented in two seminal review papers by Keller-Wood \& Dallman (1984) and Dallman et al. (1987). These reviews describe the empirical basis for three separate phases of glucocorticoid negative feedback that could be distinguished by time course: 1) fast feedback $(<10 \mathrm{~min}$ onset with short lasting duration of $\sim 5-15 \mathrm{~min}$ ), 2) intermediate feedback (onset between $0 \cdot 5$ and $2 \mathrm{~h}$ and duration of $\sim 6-12 \mathrm{~h}$ ), and 3) slow feedback (onset after constant glucocorticoid exposure for $12 \mathrm{~h}$ or more and duration that may last for days). Those three phases of feedback are also believed to be separable by mechanism of action. Some supporting evidence is that fast feedback does not require altered gene transcription and de novo protein synthesis, whereas intermediate and slow feedback do (Brattin \& Portanova 1977, Keller-Wood \& Dallman 1984, Dayanithi \& Antoni 1989, Hinz \& Hirschelmann 2000). Intermediate and slow feedback have been proposed to differ according to whether glucocorticoids inhibit stimulus-induced hormone secretion (intermediate feedback) or both hormone secretion and hormone production (slow feedback; Keller-Wood \& Dallman 1984).

Surprisingly, there has been very little advance in the subsequent 25 years in determination of the underlying molecular mechanisms by which glucocorticoids produce negative feedback regulation of the HPA axis. For example, 
it remains undetermined whether each of those phases of feedback function are operative at both the hypothalamic paraventricular nucleus (PVN) and the anterior pituitary elements of the HPA axis (intrinsic negative feedback). Glucocorticoid negative feedback also appears to depend on glucocorticoid alteration of neural input to the PVN (extrinsic negative feedback); however, the time course for that influence has not been explored. Although the mechanism of slow feedback is believed to be largely due to glucocorticoid inhibition of corticotrophin releasing hormone $(\mathrm{CRH})$ and $\mathrm{ACTH}$ production, the molecular mechanism(s) of intermediate feedback remain unknown (Keller-Wood \& Dallman 1984). Moreover, it remains to be determined whether intermediate feedback depends on single or multiple glucocorticoid effects. The prospect of multiple glucocorticoid effects within the intermediate feedback time frame has been questioned based on in vitro study of corticotrophs (Dayanithi \& Antoni 1989). There is also absence of in vivo studies that clearly illustrate the presence of separate dissociable glucocorticoid intermediate negative feedback effects within the same study and experimental conditions. In addition, in vivo studies have not examined whether de novo protein synthesis is required for glucocorticoid inhibition within the intermediate feedback time frame. Because intermediate glucocorticoid inhibitory effects are evident within $1 \mathrm{~h}$ after treatment (Ginsberg et al. 2003, 2006), establishing the requirement for de novo protein synthesis is warranted. Determination of the mechanisms of glucocorticoid negative feedback has clinical importance. There is considerable evidence for altered negative feedback function associated with a wide range of clinical disorders (e.g. depression, post-traumatic stress disorder, type II diabetes, chronic fatigue syndrome, fibromyalgia, and chronic facial pain) and associated precursor conditions (e.g. obesity and systemic hypertension; Pariante \& Miller 2001, Yehuda et al. 2004, Bruehl et al. 2007, Jerjes et al. 2007, Wingenfeld et al. 2007, Wirtz et al. 2007, Galli et al. 2009, Mattsson et al. 2009).

The goal of this study was to determine whether a phasic increase in corticosterone (CORT) comparable to a moderate stressor would produce, over the course of 1-3 hours, multiple glucocorticoid negative feedback effects. Specifically, we sought to determine whether separate glucocorticoid effects could be identified by anatomical site of action, time course, and dependence on de novo protein synthesis. The key strategy that we adopted for these studies was not only to monitor effects of CORT on stress-induced HPA axis hormone secretion, but also to monitor CORT effects on stress-induced gene expression. We and others have found that a number of genes are rapidly induced (within $15 \mathrm{~min}$ ) by acute stress within the cellular elements of the HPA axis (Imaki et al. 1995, Kovács \& Sawchenko 1996, Pace et al. 2009). Some of those genes (e.g. c-fos) function as immediate early genes in a wide range of neuronal and endocrine cell populations. Other genes (e.g. crh gene and pro-opiomelanocortin, pomc, gene) are rapidly induced within a restricted population of cells. Rapid induction of the $c r h$ and pomc genes in the PVN and anterior pituitary respectively can be observed when measuring the levels of their primary transcript (hnRNA; Autelitano et al. 1989, Herman et al. 1992, O'Connor et al. 2005).

In this study, we examined the effect of CORT pretreatment on stress-induced $c-f o s$, crh, and pomc gene expression, under normal conditions and in the presence of systemic protein synthesis blockade. Both crh and pomc genes are believed to be direct targets for glucocorticoid receptor (GR)-mediated CORT repression (Dostert \& Heinzel 2004). On the other hand, the $c$-fos gene appears not to be directly repressed by CORT (Ginsberg et al. 2003, 2006), although its expression can be inhibited by long-term glucocorticoid treatment (Umemoto et al. 1997). In previous studies, we have found that $1 \mathrm{~h}$ glucocorticoid pretreatment is not sufficient to suppress subsequent restraint-induced c-fos mRNA in the PVN or anterior pituitary (Ginsberg et al. 2003, 2006). It appears then that $c r h$, pomc, and c-fos gene expression all reflect aspects of recent stress-induced HPA axis cellular excitation. However, c-fos gene expression may only reflect glucocorticoid actions as they alter stress-induced intercellular and intracellular signals that converge on the $c$-fos gene promoter. Thus, we may be able to determine the influence of phasic CORT on stress-induced excitatory input to the PVN (i.e. extrinsic feedback) by examining $c$-fos mRNA. In contrast, the expression of $c r h$ and pomc genes appears to integrate information about both the direct presence of activated GRs and upstream signaling events.

\section{Materials and Methods}

\section{Animals}

Young adult male Sprague-Dawley rats (270-315 g) were purchased from a commercial vendor (Harlan Labs, Indianapolis, IA, USA) and were given a 2 -week period of acclimation to the University of Colorado animal facility and housing conditions before experimental use. The housing

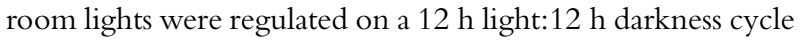
(lights on at $0700 \mathrm{~h}$ ), and the room temperature was maintained at $22 \pm 1{ }^{\circ} \mathrm{C}$. Rats were housed two per cage. Food (Teklad Rodent Diet 8640; Harlan Labs) and tap water were available ad libitum. The housing and testing area consisted of a procedure area surrounding four separate interior home rooms that were each sound attenuated with independent air supply and exhaust. This arrangement minimized the extent to which rats while in their home room were exposed to any extraneous sounds or odors associated with the various procedures on the test day. Procedures for ethical treatment of animals conformed to the guidelines found in the 'Guide for the Care and Use of Laboratory Animals' (DHHS Publication No. NIH 80-23, revised $1996 \mathrm{edn}$ ), and all procedures were approved by the University of Colorado Institutional Animal Care and Use Committee. 


\section{Drugs}

Protein synthesis inhibitor cycloheximide (CX; $100 \mathrm{mg} / \mathrm{ml}$ ) was dissolved in sterile $0.9 \%$ saline on the test day. CX was purchased from Sigma-Aldrich. CORT $(2.5 \mathrm{mg} / \mathrm{ml})$ was dissolved on the test day in a mixture of 10\% ethanol, $30 \%$ propylene glycol, and 60\% saline. CORT was purchased from Steraloids (Newport, RI, USA).

\section{Experimental procedure}

The experiment was comprised of 16 separate treatment groups $(2 \times 2 \times 2 \times 2$ factorial between-subjects design; $n=6$; $N=96$ rats). The four treatment factors were 1) protein synthesis inhibition (CX or vehicle), 2) CORT pretreatment (CORT or vehicle), 3) time of CORT pretreatment (1 or $3 \mathrm{~h}$ ), and 4) stress challenge (restraint or home cage; Fig. 1). On the test day, rats were injected with $\mathrm{CX}(100 \mathrm{mg} / \mathrm{kg}$, s.c.) or vehicle $30 \mathrm{~min}$ before injection with CORT $(2.5 \mathrm{mg} / \mathrm{kg}$, i.p.) or vehicle. This dose of $\mathrm{CX}$ has been reported to not alter in the PVN stress-induced $c r h$ gene expression or activation of the cAMP response element-binding protein, while effectively blocking $90 \%$ of stress-induced Fos protein expression (Kovács et al. 1998). This finding indicates that this systemic dose of CX has effective inhibitory effects within the central nervous system on stress-induced protein production within the PVN. This exogenous CORT treatment procedure produces plasma CORT levels in rats that closely match the endogenous CORT levels and time course associated with a moderate intensity stressor, such as restraint (Pace et al. 2009). After each injection, rats were returned to their home cage and home room. Rats were then challenged 1 or $3 \mathrm{~h}$ later with stress (15 min restraint) or remained in their home cage. For restraint challenge, rats were placed in clear plexiglass tubes $(23.5 \mathrm{~cm}$ in length and $7 \mathrm{~cm}$ in diameter; with multiple air holes) with their tails protruding. The size of the tube restricted lateral, forward, and backward movements, but did not interfere with breathing. Rats were decapitated immediately after 15 min restraint or at a comparable time after drug pretreatment for the no stress comparison. Stress-challenged rats were restrained in an area adjacent to their home room, whereas non-stressed rats remained in their home cage and home room until decapitation. Paired rats were placed into

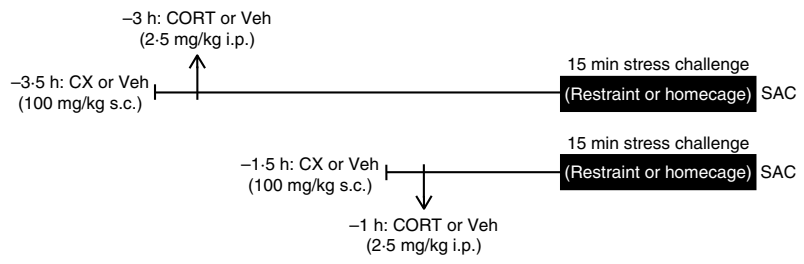

Figure 1 Test day timeline for CX and CORT pretreatment of stresschallenged rats. Rats were pretreated with CORT or CORT-vehicle either 3 or $1 \mathrm{~h}$ before restraint challenge. CX or CX-vehicle treatment was administered $0.5 \mathrm{~h}$ before CORT or CORT-vehicle. Restraint-challenged rats were killed (SAC) immediately after 15 min restraint. No-stress control rats were killed at the comparable time point. $n=6 ; N=96$ rats. the same stress condition to minimize any disturbance that may be caused by removing a rat from its cage mate. This ensured that blood and tissue samples were collected under the same conditions. Trunk blood collection and brain extraction were rapidly performed after decapitation in an area adjacent to their home room. Test day procedures occurred between 0800 and $1300 \mathrm{~h}$, and time of day was counterbalanced across treatment groups. Rats were habituated to both s.c. and i.p. injections by poking rats with the blunt end of a $1 \mathrm{ml}$ syringe (no needle attached) for 2 min over a 2-day period before testing. Experimentation was divided into two separate cohorts of rats, $n=3$ per treatment group for each cohort, and data were then pooled for the two cohorts.

\section{ACTH and CORT assays}

Trunk blood was collected into EDTA-containing vacutainer tubes from Becton-Dickinson (Franklin Lakes, New Jersey, USA), placed on wet ice and then centrifuged for $15 \mathrm{~min}$ $\left(4^{\circ} \mathrm{C}\right)$. Plasma was then aliquoted into storage microfuge tubes and snap-frozen on dry ice. The entire procedure was completed within $45 \mathrm{~min}$ after blood collection. ACTH $(\mathrm{pg} / \mathrm{ml})$ was determined in duplicate $(100 \mu \mathrm{l}$ plasma) by RIA as adapted and described previously from a single-stage assay protocol (Nicholson et al. 1984, Pace et al. 2009). Radiolabeled ${ }^{125}$ I ACTH was obtained from DiaSorin (Minneapolis, MN, USA). Primary ACTH anti-serum Rb 7 (diluted to a final concentration of 1:30 000) was kindly donated by Dr William Engeland (University of Minnesota). Sensitivity for the ACTH assay was $\sim 15 \mathrm{pg} / \mathrm{ml}$. The intra-assay coefficient of variability was $6 \%$, and the inter-assay coefficient of variability was $6 \%$.

Measurement of plasma CORT $(\mu \mathrm{g} / 100 \mathrm{ml})$ was conducted in duplicate using $20 \mu \mathrm{l}$ of plasma with an enzyme immunoassay kit (Assay Design, Ann Arbor, MI, USA) according to the manufacturer's instructions. Sensitivity for the CORT assay was $\sim 0.13 \mu \mathrm{g} / 100 \mathrm{ml}$. The intra-assay coefficient of variability was $4 \%$, and the inter-assay coefficient of variability was $6 \%$.

\section{In situ hybridization histochemistry}

Brains and pituitaries were rapidly removed, collected after decapitation, frozen in chilled isopentane (at temperatures held between -30 and $-40{ }^{\circ} \mathrm{C}$ ), and stored at $-80^{\circ} \mathrm{C}$. Coronal brain sections (12 $\mu \mathrm{m}$ thick) were collected through the extent of the PVN $\sim 1.80 \mathrm{~mm}$ posterior to bregma (Paxinos et al. 1980). Horizontal pituitary sections $(12 \mu \mathrm{m}$ thick) were collected from the middle portion of the tissue. All tissue were sectioned on a cryostat (Leica Microsystems, model 1850, Bannockburn, IL, USA). Both brain and pituitary sections were thaw mounted onto poly-L-lysine-coated slides and stored at $-80{ }^{\circ} \mathrm{C}$. For in situ hybridization, tissue was postfixed in buffer solution containing $4 \%$ paraformaldehyde for $1 \mathrm{~h}$, at room temperature and then processed as published previously (Girotti et al. 2006). ${ }^{35}$ S-UTP-labeled cRNA probes for $c r h$ hnRNA, $c$-fos mRNA, and pomc hnRNA were 
generated from cDNA subclones in transcription vectors using standard in vitro transcription methodology (Promega; Girotti et al. 2006). Rat c-fos cDNA clone was obtained from Dr T Curran, St Jude Children's Research Hospital, Memphis, TN, USA. A portion of rat $c r h$ intron was provided as courtesy by Dr R T Thompson, University of Michigan. A portion of rat pomc intron was provided as courtesy by Dr Stanley Watson, University of Michigan. The identity of all cloned DNA was verified by DNA sequencing (University of Colorado Molecular, Cellular and Developmental Biology sequencing facility). After the hybridization assay procedure, slides were exposed to X-ray film (Kodak Biomax MR film): 3 weeks for $c r h$ hnRNA, 10 days for $c$-fos mRNA, and $12 \mathrm{~h}$ (for intermediate lobe analysis) or 2 days (for anterior lobe analysis) for pomc hnRNA. Separate in situ hybridization assays were performed for each experimental cohort.

\section{Image analysis}

Semiquantitative analyses were performed on digitized images from X-ray films using the linear range of the gray values obtained from an acquisition system (Northern Light lightbox, model B 95; CCD camera, model XC-77, Sony, Tokyo, Japan; image capture with National Institutes of Health scion Image v1.59 software) as described previously (Campeau et al. 2002). Signal pixels of the region of interest were defined as those with a gray value of 3.5 S.D. above the mean gray value of background (lateral hypothalamus or corpus callosum). The PVN region was determined by matching digitized rat hypothalamic structures with rat brain atlas images. The product of the number of pixels and the average pixel values above the set background was then computed to give an integrated mean gray level measure. Between four and eight brain sections and between six and eight anterior pituitary sections were used for analysis of each rat for all genes. The data were normalized for each cohort by expressing relative integrated gray levels as a percent of the average value for the restraint challenged rats that had received vehicle injections 3 and $3 \cdot 5 \mathrm{~h}$ earlier.

\section{Statistical analysis}

Statistical analyses were conducted using the SPSS statistical analysis program 10.5 (Chicago, IL, USA) for Macintosh operating system. In order to minimize heteroscedasticity, the data were $\log$ transformed for inferential statistical analyses. The data were first analyzed by four-way ANOVAs in order to determine whether there was a main effect of CX treatment and interaction between $\mathrm{CX}$ and the other treatment factors. Separate three-way ANOVAs were then conducted in order to assess the effects of stress, CORT, and pretreatment time within non-CX (vehicle)- or CX-treated rats. In cases where there was an overall significant F-test, pairwise comparisons of interest were assessed by Fisher's least significant difference test (FLSD), $\alpha=0 \cdot 05$. Graphed data depict the non-log transformed group means \pm s.E.M.

\section{Results}

\section{Hormone levels}

As expected, without CX pretreatment, $15 \mathrm{~min}$ of restraint significantly increased plasma ACTH levels (stress effect: $\left.F_{1,40}=7 \cdot 6, P<0 \cdot 01\right)$, and this was suppressed by both 1 and $3 \mathrm{~h}$ CORT pretreatment (CORT pretreatment effect: $F_{1,40}=11 \cdot 8, \quad P<0 \cdot 01$; Fig. 2A). Systemic pretreatment with CX induced high secretion of ACTH (CX effect: $F_{1,84}=327 \cdot 2, P<0 \cdot 01$; Fig. $2 \mathrm{~B}$ ) that declined over the $3.5 \mathrm{~h}$ after treatment, but nevertheless remained higher than levels produced by restraint (CX by time effect: $F_{1,84}=17 \cdot 3$, $P<0 \cdot 01)$. Neither acute stress nor CORT pretreatment had an effect on the high ACTH levels present after CX
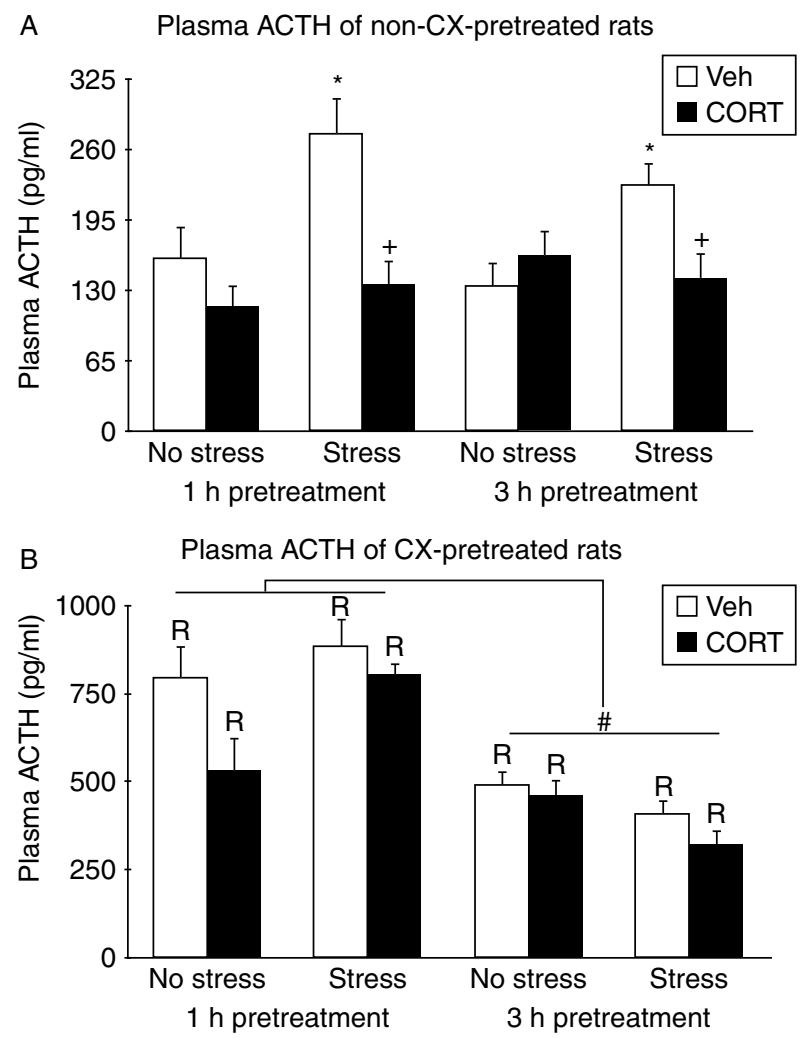

Figure 2 Effects of CORT pretreatment on basal and stress-induced ACTH plasma hormone levels of non-CX- or CX-pretreated rats. (A) In the absence of CX pretreatment, restraint significantly increased plasma ACTH levels, and this was suppressed by both 1 and $3 \mathrm{~h}$ CORT pretreatment. (B) Systemic pretreatment with $\mathrm{CX}$ induced high secretion of ACTH that declined over the $3.5 \mathrm{~h}$ after treatment. CX prevented the suppressive effect of CORT pretreatment on plasma ACTH levels. ${ }^{*}$, significant stress effect within same drug condition and pretreatment time point $(P<0 \cdot 05$, FLSD); + , significant CORT effect compared with vehicle-treated rats within the same pretreatment time and stress condition $(P<0 \cdot 05, \mathrm{FLSD}) ; \#$, significant difference in ACTH secretion between 1 and $3 \mathrm{~h}$ pretreatments within $\mathrm{CX}$-treated rats $(P<0 \cdot 05$, FLSD); $R$, significant difference between $C X$-pretreated rats $(B)$ compared with the corresponding non-CX-treated rats $(\mathrm{A})$ $(P<0 \cdot 05$, FLSD $)$. 
treatment. Thus, CX pretreatment prevented the suppressive effect of 1 and $3 \mathrm{~h}$ CORT pretreatment on plasma ACTH levels.

In the absence of CX pretreatment, endogenous CORT levels were also significantly increased by $15 \mathrm{~min}$ of restraint (evident in vehicle pretreatment groups; Fig. 3A). CORT pretreatment $3 \mathrm{~h}$ prior to restraint suppressed stress-induced endogenous CORT production (stress by CORT interaction: $F_{1,40}=11 \cdot 28, \quad P<0 \cdot 01$, followed by FLSD post hoc test, $P<0 \cdot 01)$. We could not determine whether $1 \mathrm{~h}$ CORT pretreatment also suppressed endogenous CORT production, because exogenous CORT levels resulting from the $1 \mathrm{~h}$ pretreatment injection had not yet cleared from the systemic blood circulation (high CORT levels in no-stress rats $1 \mathrm{~h}$, but
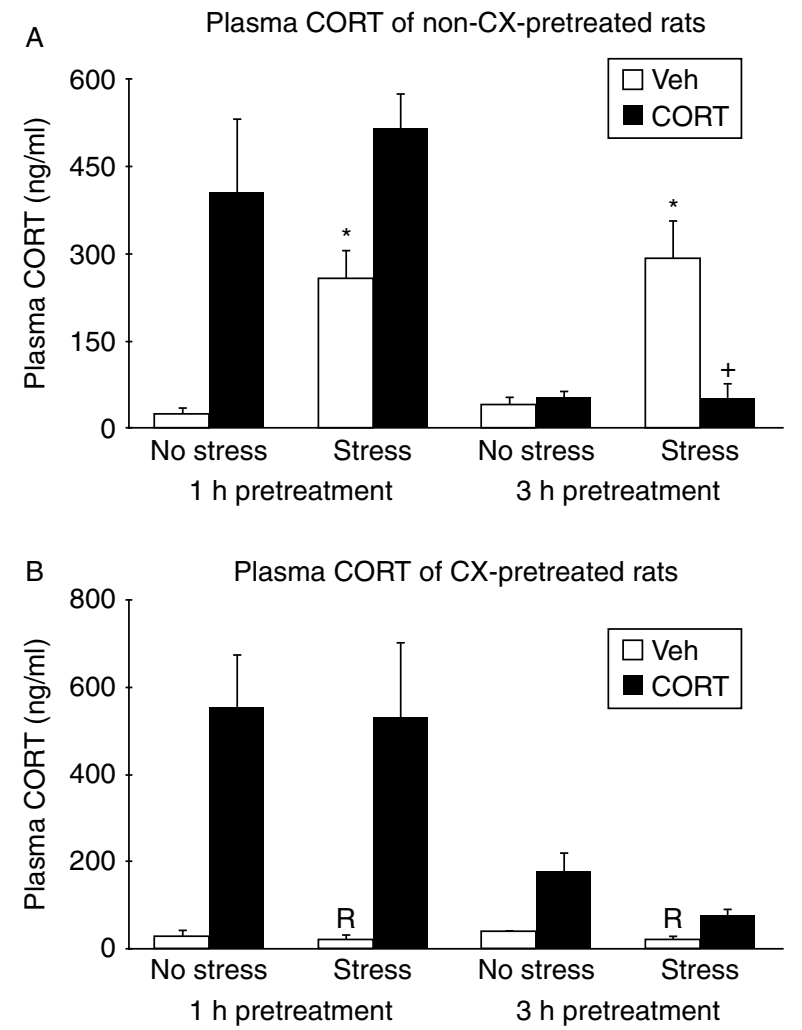

Figure 3 Effects of CORT pretreatment on basal and stress-induced CORT levels of non-CX- or CX-pretreated rats. (A) In the absence of CX pretreatment, endogenous CORT levels were significantly increased by $15 \mathrm{~min}$ of restraint (evident in vehicle pretreatment groups). Exogenous CORT levels cleared from the circulation by $3 \mathrm{~h}$ after treatment, at which time it was evident that stress-induced endogenous CORT was suppressed. (B) Systemic pretreatment with CX prevented stress-induced production of endogenous CORT and appeared to interfere with the rate of clearance of exogenous CORT. $*$, significant stress effect within same drug condition and pretreatment time point $(P<0 \cdot 05$, FLSD); + , significant CORT effect compared with vehicle-treated rats within the same pretreatment time and stress condition $(P<0 \cdot 05, \mathrm{FLSD}) ; \mathrm{R}$, significant difference between $\mathrm{CX}$-pretreated rats $(\mathrm{B})$ compared with the corresponding non-CX-treated rats $(\mathrm{A})(P<0 \cdot 05, \mathrm{FLSD})$. not $3 \mathrm{~h}$, after CORT treatment; Fig. 3A). Strikingly, endogenous CORT (Fig. 3B) production was very low in $\mathrm{CX}$-treated rats, despite the high levels of ACTH secretion (CX by CORT interaction: $F_{1,84}=20 \cdot 7, P<0 \cdot 01$; Fig. $2 B$ ).

\section{PVN gene expression}

Restraint (15 min) significantly induced PVN $c r h$ hnRNA (stress effect: $F_{1,38}=35 \cdot 0, P<0 \cdot 01$; Fig. $4 \mathrm{~A}$ and $\mathrm{B}$ ). Treatment with CORT $1 \mathrm{~h}$, but not $3 \mathrm{~h}$, prior to restraint suppressed stress-induced PVN $c r h$ hnRNA (time by CORT interaction: $F_{1,38}=12 \cdot 0, P<0 \cdot 01$; Fig. $4 \mathrm{~A}$ and B). Systemic pretreatment with CX increased PVN $c r h$ hnRNA levels in all groups, irrespective of acute stress or CORT treatment condition (CX effect: $F_{1,71}=59 \cdot 2, P<0 \cdot 01$; Fig. 4C). However, CX pretreatment did not block the suppressive effect of $1 \mathrm{~h}$ CORT pretreatment on $\mathrm{cr}$ hnRNA levels (CORT effect: $F_{1,38}=15 \cdot 2, P<0 \cdot 01$, followed by FLSD, $P<0 \cdot 01$; Fig. $4 \mathrm{C}$ and D).

Restraint (15 min) also increased PVN c-fos mRNA (stress effect: $F_{1,37}=68 \cdot 7, P<0 \cdot 01$; Fig. $5 \mathrm{~A}$ and $\mathrm{B}$ ). In contrast to crh hnRNA, neither $1 \mathrm{~h}$ nor $3 \mathrm{~h}$ CORT pretreatment significantly suppressed restraint-induced PVN $c$-fos mRNA (Fig. 5A and B). Systemic pretreatment with CX increased PVN $c$-fos mRNA levels in all groups, irrespective of acute stress or CORT treatment condition (CX effect: $F_{1,76}=342 \cdot 9, P<0 \cdot 01$; Fig. $5 \mathrm{C}$ and D).

\section{Pituitary pomc gene expression}

Restraint (15 min) significantly induced pomc hnRNA in the anterior pituitary (stress effect: $F_{1,38}=12 \cdot 4, P<0 \cdot 01$; Fig. $6 \mathrm{~A}$ and $\mathrm{E}$ ) and in the intermediate lobe of the pituitary (stress effect: $F_{1,34}=5 \cdot 7, P<0 \cdot 05$; Fig. $6 \mathrm{C}$ ). CORT pretreatment (1 and $3 \mathrm{~h}$ ) suppressed both basal and stress-induced pomc hnRNA levels within the anterior pituitary (CORT effect: $F_{1,38}=35.9, P<0 \cdot 01$; Fig. $6 \mathrm{~A}$ and $\left.\mathrm{E}\right)$, but had no effect on pomc hnRNA levels within the intermediate lobe. Systemic CX pretreatment tended to increase basal, but not stressinduced, pomc hnRNA in the anterior pituitary (Fig. 6B and E). CX did not block the suppressive effects of $1 \mathrm{~h} \mathrm{CORT}$ pretreatment on basal and stress-induced anterior pituitary pomc hnRNA expression (FLSD, $P<0 \cdot 01$; Fig. 6B and E), but $\mathrm{CX}$ pretreatment blocked the suppressive effects of $3 \mathrm{~h}$ CORT pretreatment on those measures (CORT by time interaction for $\mathrm{CX}$ pretreated rats: $F_{1,38}=18 \cdot 4, P>0 \cdot 01$; Fig. $6 \mathrm{~B}$ and $\mathrm{E})$. CX pretreatment had no effect on basal or stress-induced pomc hnRNA in the intermediate lobe of the pituitary, Fig. 6D.

\section{Pituitary c-fos gene expression}

Restraint (15 min) produced a large increase in c-fos mRNA within the anterior pituitary (stress effect: $F_{1,34}=72 \cdot 6$, $P<0 \cdot 05$; Fig. $7 \mathrm{~A}$ and $\mathrm{E})$ and in the intermediate lobe of the pituitary (stress effect: $F_{1,38}=38 \cdot 8, P<0 \cdot 01$ ). 


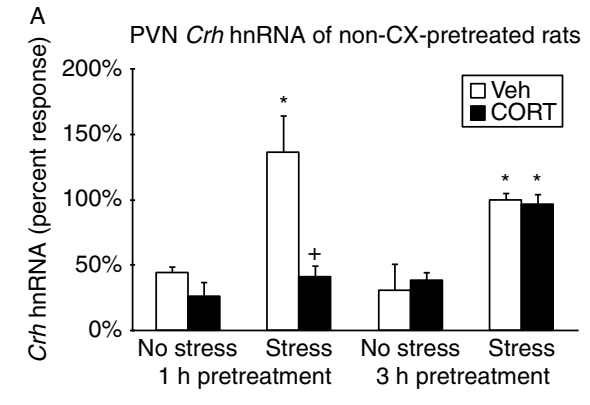

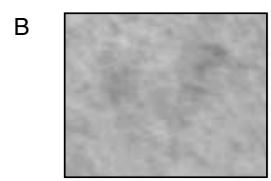

No stress

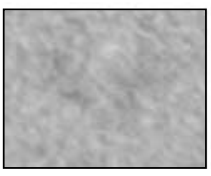

Stress $+1 \mathrm{~h}$ CORT

pretreatment

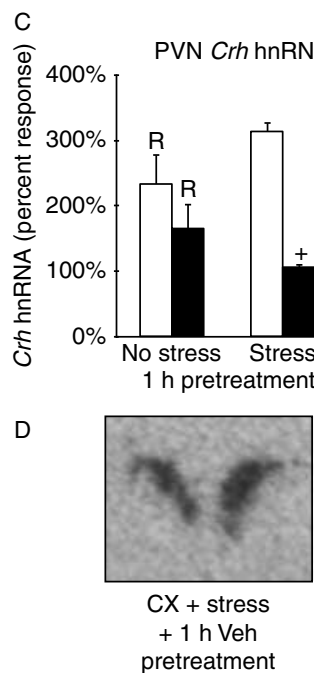

pretreatment

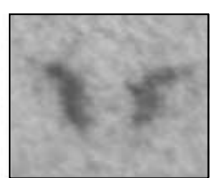

Stress

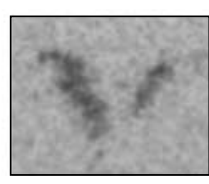

Stress $+3 h$ CORT

pretreatment

\section{CX-treated rats}
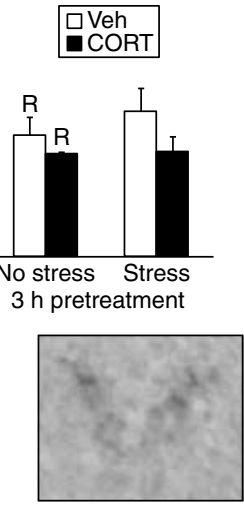

$\mathrm{CX}+$ stress $+1 \mathrm{~h}$ CORT pretreatment

Figure 4 Effects of CORT pretreatment on basal and stress-induced PVN crh hnRNA levels of non-CX- or CX-pretreated rats. (A, B) In the absence of CX pretreatment, restraint significantly induced PVN crh hnRNA, and pretreatment with CORT $1 \mathrm{~h}$, but not $3 \mathrm{~h}$, prior to restraint suppressed this effect. (C, D) Systemic pretreatment with CX increased PVN crh hnRNA levels in all groups but did not block the suppressive effect of $1 \mathrm{~h}$ CORT pretreatment on crh hnRNA levels. Panels B and D show representative autoradiographic images of the bilateral PVN portion of coronal brain sections from key comparison conditions depicted in panels $\mathrm{A}$ and $\mathrm{C}$ respectively. Values are presented as a percentage of the mean value of the non-CX-pretreated stressed $3 \mathrm{~h}$ vehicle rats. ${ }^{*}$, significant stress effect within same drug condition and pretreatment time point $(P<0 \cdot 05, \mathrm{FLSD}) ;+$, significant CORT effect compared with vehicle-treated rats within the same pretreatment time and stress condition $(P<0 \cdot 05$, FLSD); R, significant difference between $C X$-pretreated rats $(C)$ compared with the corresponding non-CX-treated rats $(\mathrm{A})(P<0 \cdot 05, \mathrm{FLSD})$.

Pretreatment with CORT $3 \mathrm{~h}$, but not $1 \mathrm{~h}$, prior to restraint suppressed stress-induced anterior pituitary c-fos mRNA levels (CORT by time interaction: $F_{1,34}=8 \cdot 4, P>0 \cdot 05$; Fig. 7A and E), but had no effect on $c$-fos mRNA levels within the intermediate lobe (Fig. 7C). Systemic pretreatment with CX moderately increased anterior pituitary c-fos mRNA levels regardless of stress and CORT treatment (CX effect: $F_{1,70}=222, P>0.05$, Fig. $7 \mathrm{~B}$ and E). CX pretreatment blocked the suppressive effect of $3 \mathrm{~h}$ CORT pretreatment on pituitary c-fos mRNA levels (CORT by CX interaction: $F_{1,70}=8 \cdot 4, \quad P>0.05$ Fig. $7 \mathrm{~B}$ and E). CX pretreatment increased basal, but not stress-induced, c-fos mRNA in the intermediate lobe of the pituitary (stress by CX interaction: $F_{1,70}=72 \cdot 8$; Fig. 7D).

\section{Discussion}

We examined the HPA axis negative feedback effects evident 1 or $3 \mathrm{~h}$ after a phasic increase in systemic CORT. Both 1 and $3 \mathrm{~h}$ CORT pretreatment completely suppressed the ACTH secretion response to subsequent restraint challenge, and in both cases, there was no suppressive effect in the presence of acute protein synthesis inhibition. CORT also suppressed subsequent stress-induced immediate early gene expression, but the pattern of suppression varied for each gene ( $\mathrm{crh}$, pomc, or $c$-fos) depending on anatomical location (PVN, anterior pituitary, and intermediate pituitary), time interval (1 or $3 \mathrm{~h}$ ), and protein synthesis inhibition.

Stress-induced $c r h$ and pomc gene expression in the PVN and anterior pituitary respectively was completely suppressed by $1 \mathrm{~h}$ CORT pretreatment. In contrast to the suppressive effect of $1 \mathrm{~h}$ CORT pretreatment on ACTH secretion, suppression of $c r h$ and pomc gene expression occurred even in the presence of protein synthesis inhibition. Our results support other studies indicating that those two genes are subject to direct inhibitory control by glucocorticoids, probably acting through GR (Drouin et al. 1993, Guardiola-Diaz et al. 1996, Reichardt \& Schütz 1998, Reichardt et al. 1998a,b, Erdmann et al. 2008). Glucocorticoid-dependent inhibition of $\mathrm{crh}$ and pomc gene expression likely involves both direct gene repression via activated GR binding of DNA (negative glucocorticoid response element) and indirect gene repression via activated GR binding with stimulatory transcription factors (Dostert \& Heinzel 2004). The absence of an inhibitory effect of CORT on pome gene expression in the intermediate lobe of the pituitary can be explained by the fact that in adult rats, melanotrophs express very little, if any, GR (McGimsey et al. 1991, Ozawa et al. 1999, Ginsberg et al. 2006).

The failure of $3 \mathrm{~h}$ CORT pretreatment to suppress subsequent stress-induced PVN crh gene expression is a novel finding and may be accounted for by the complete clearance of exogenous CORT that we observed by that point in time. Thus, there was likely no longer elevated GR activation $3 \mathrm{~h}$ after CORT treatment (Meaney et al. 1988, Freeman \& Yamamoto 2001). A downregulation of GR 


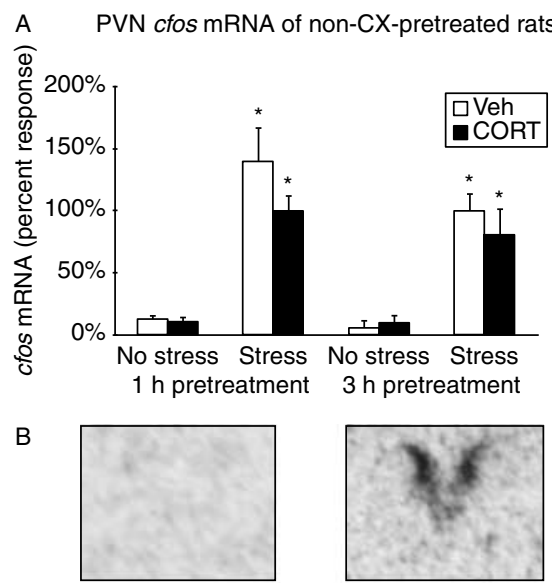

No stress

Stress

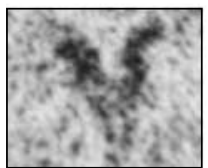

Stress $+1 \mathrm{~h}$

CORT

pretreatment

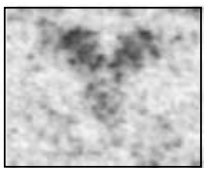

Stress $+3 h$

CORT

pretreatment

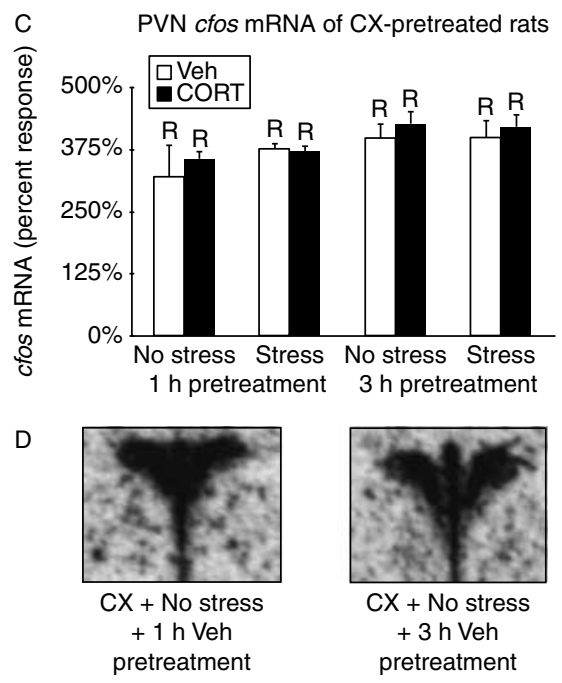

Figure 5 Effects of CORT pretreatment on basal and stressinduced PVN c-fos mRNA levels of non-CX- or CX-pretreated rats. (A, B) In the absence of $\mathrm{CX}$ pretreatment, restraint induced PVN $c$-fos mRNA, and neither $1 \mathrm{~h}$ nor $3 \mathrm{~h}$ CORT pretreatment suppressed that induction. (C, D) Systemic pretreatment with CX increased PVN $c$-fos mRNA levels in all groups, irrespective of acute stress or CORT treatment condition. Panels B and D show representative autoradiographic images of the bilateral PVN portion of coronal brain sections from key comparison conditions depicted in panels $A$ and $C$ respectively. Values are presented as a percentage of the mean value of the nonCX-pretreated stressed $3 \mathrm{~h}$ vehicle rats. ${ }^{*}$, significant stress effect within same drug condition and pretreatment time point $(P<0 \cdot 05, \mathrm{FLSD}) ; \mathrm{R}$, significant difference between CX-pretreated rats $(C)$ compared with the corresponding non-CX-treated rats $(A)$ $(P<0 \cdot 05$, FLSD $)$. expression in the brain $3 \mathrm{~h}$ after CORT injection is not a likely alternative explanation for the lack of an inhibitory effect. A previous study found an absence of changes in GR mRNA or protein expression within this time frame after injection with a higher dose of CORT (Herman \& Spencer 1998). The apparent tight coupling of $\mathrm{crh}$ gene expression to activated GR levels may allow for glucocorticoid regulation of PVN crh gene expression to be especially responsive to pulsatile secretion of CORT (Lightman et al. 2008, Stavreva et al. 2009). The residual effects that we observed for some other measures $3 \mathrm{~h}$ after CORT pretreatment may be a result of CORT alteration of cellular protein levels that was maintained for several hours. In keeping with that notion, all of the inhibitory effects that we observed after $3 \mathrm{~h} \mathrm{CORT}$ pretreatment were absent in the presence of protein synthesis inhibition. Interestingly, it appears that there was a dual regulatory influence of CORT on corticotroph pomc gene expression - an immediate protein synthesis-independent repressive effect that was evident within $1 \mathrm{~h}$, and a delayed protein synthesis-dependent inhibitory effect that was evident by $3 \mathrm{~h}$.

In contrast to CORT regulation of $\mathrm{crh}$ and pomc gene expression, stress-induced $c$-fos gene expression in the PVN was not suppressed by $1 \mathrm{~h}$ CORT pretreatment. That result replicates our previous findings (Ginsberg et al. 2003, 2006) and indicates that CORT did not inhibit the intercellular and intracellular signals that led to stress-induced $c$-fos gene induction in the PVN. The $c$-fos gene is induced by a wide range of intracellular signal transduction pathways (Kovács 1998, Nestler et al. 2001). Consequently, the absence of an effect of 1 or $3 \mathrm{~h} \mathrm{CORT} \mathrm{pretreatment} \mathrm{on} \mathrm{stress-induced} c$-fos gene expression suggests that there was a corresponding absence of CORT inhibition of the stress-induced stimulatory input to the PVN (i.e. absence of extrinsic negative feedback). Both the hippocampus/ventral subiculum and prefrontal cortex are brain regions that have been implicated as important sites of extrinsic glucocorticoid negative feedback (Jacobson \& Sapolsky 1991, Feldman \& Weidenfeld 1993, Herman \& Mueller 2006). However, it remains to be determined whether manipulation of CORT levels within those brain regions has a short-term (within $3 \mathrm{~h}$ ) effect on HPA axis activity.

We found in this study that $1 \mathrm{~h}$ CORT pretreatment also failed to suppress overall stress-induced c-fos mRNA in the anterior pituitary. A similar inference as discussed earlier for c-fos gene expression in the PVN could be applied to the anterior pituitary. Thus, the data may indicate that $1 \mathrm{~h}$ CORT pretreatment did not inhibit the release of stressinduced ACTH secretagogues. However, we have recently found that microinfusion of CORT directly in the PVN is sufficient to inhibit the ACTH and anterior pituitary pomc hnRNA response to restraint challenge when administered $1 \mathrm{~h}$ later (Weiser \& Spencer 2009). Most studies have determined that corticotrophs comprise $<10 \%$ of the endocrine cells in the rat anterior pituitary (Levy 2002). Consequently, if there was a selective CORT-dependent 

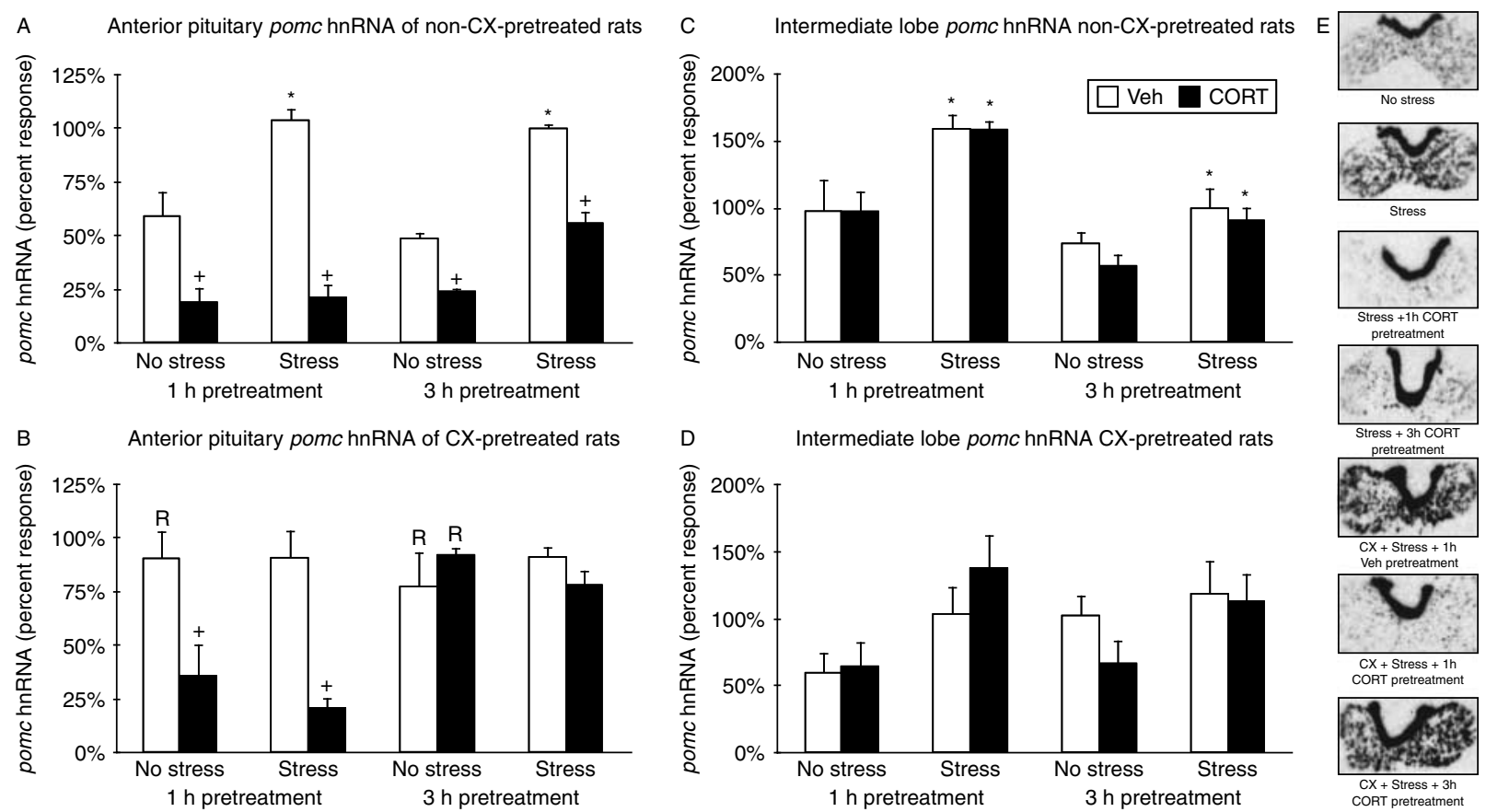

CX + Stress $+1 \mathrm{~h}$

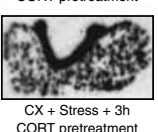

Figure 6 Effects of CORT pretreatment on basal and stress-induced pituitary anterior lobe and intermediate lobe pomc hnRNA levels of nonCX- or CX-pretreated rats. (A) In the absence of CX pretreatment, restraint induced pomc hnRNA in the anterior pituitary. CORT pretreatment $(1$ and 3 h) suppressed both basal and stress-induced pomc hnRNA levels. (B) Systemic CX pretreatment tended to increase basal, but not stress-induced, pomc hnRNA in the anterior pituitary. CX blocked the suppressive effects of $3 \mathrm{~h}$, but not of $1 \mathrm{~h}$, CORT pretreatment on those measures. (C) In the absence of CX pretreatment, restraint induced pomc hnRNA in the intermediate lobe of the pituitary, and CORT pretreatment had no effect. (D) CX pretreatment had no significant effect on basal or stress-induced pomc hnRNA in the intermediate lobe of the pituitary. Panel E shows representative autoradiographic images of the pituitaries from key comparison conditions depicted in panels A-D. Values are presented as a percentage of the mean value of the non-CX-pretreated stressed $3 \mathrm{~h}$ vehicle rats. ${ }^{*}$, significant stress effect within same drug condition and pretreatment time point $(P<0 \cdot 05$, FLSD); + , significant CORT effect compared with vehicle-treated rats within the same pretreatment time and stress condition $(P<0 \cdot 05$, FLSD); $R$, significant difference between CX-pretreated rats (B) compared with the corresponding non-CX-treated rats $(\mathrm{A})(P<0 \cdot 05$, FLSD).

inhibition of c-fos mRNA within corticotrophs, that inhibition would have been masked by the absence of a suppressive effect on stress-induced $c$-fos expression in other cell types. Lactotrophs are more abundant than corticotrophs and are also stress-reactive in the rat (Freeman et al. 2000, Takigami et al. 2008). In contrast to $1 \mathrm{~h}$ CORT pretreatment, we found that $3 \mathrm{~h}$ CORT pretreatment suppressed overall stress-induced $c$-fos gene expression in the anterior pituitary, possibly indicating a delayed CORT effect that influenced stress-induced activation of lactotrophs and corticotrophs. There is evidence for glucocorticoid suppression of stress-induced prolactin in the rat, although the time course of that effect has not been determined (Taylor et al. 1995).

It is worth noting that stress also led to a rapid increase in pomc and $c$-fos gene expression in the intermediate lobe of the pituitary, which primarily contains melanotrophs. However, neither gene induction was affected by 1 or $3 \mathrm{~h}$ CORT pretreatment. As observed earlier, a direct inhibitory effect of CORT on gene expression in the intermediate lobe of the pituitary is not to be expected due to the absence of GR expression. However, our data also suggest that the stress-responsive intercellular signals impinging on melanotrophs were not sensitive to CORT pretreatment. The dissociation in CORT responsiveness between cells of the anterior and intermediate pituitaries implies that the observed CORT effects either depended on a direct action of CORT on GR-expressing cells (anterior pituitary) or depended on an indirect effect on stress-altered secretagogues that target the anterior, but not the intermediate, lobe of the pituitary. The leading candidate secretagogues for melanotrophs are CRH and decreased dopamine (Proulx-Ferland et al. 1982, Lookingland et al. 1991). Both melanotrophs and lactotrophs are under tonic inhibitory control by dopamine, but there appear to be separate populations of dopamine neurons that regulate those two cell populations, allowing for the possibility of differential glucocorticoid dependence (Goudreau et al. 1992).

It should be noted when evaluating the results of this study that in contrast to a previous report using a similar systemic protein synthesis inhibition procedure (Kovács et al. 1998), we observed signs of strong generalized activation of the HPA axis (gene expression and hormone levels) after CX treatment. That activation may be due to systemic distress 


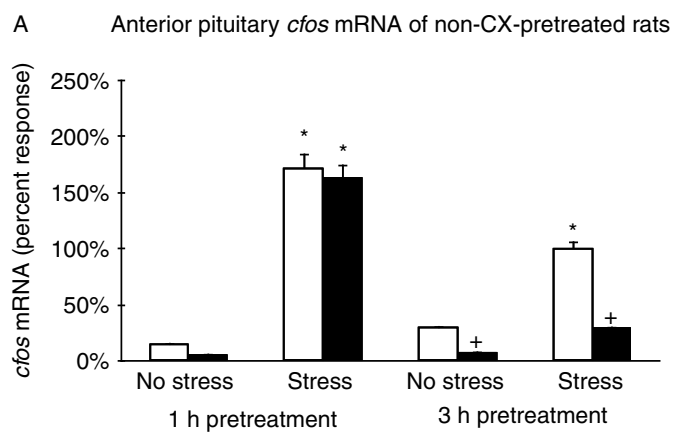

B Anterior pituitary cfos mRNA of CX-pretreated rats

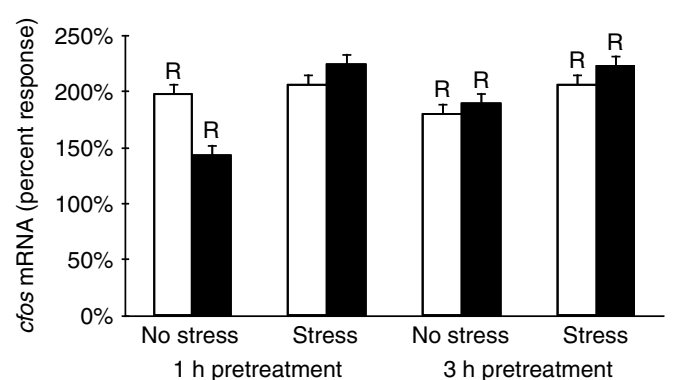

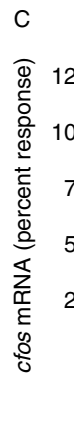

D

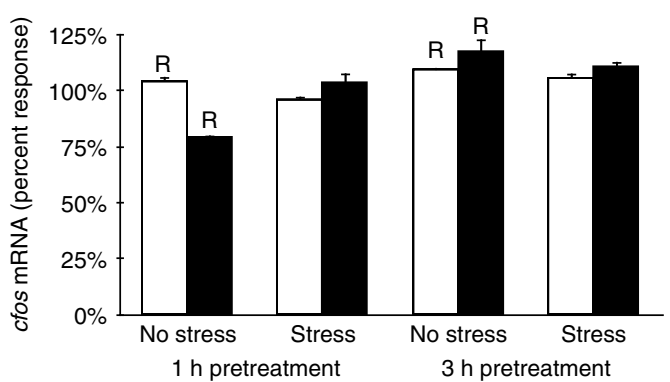

Intermediate lobe cfos mRNA non-CX-pretreated rats

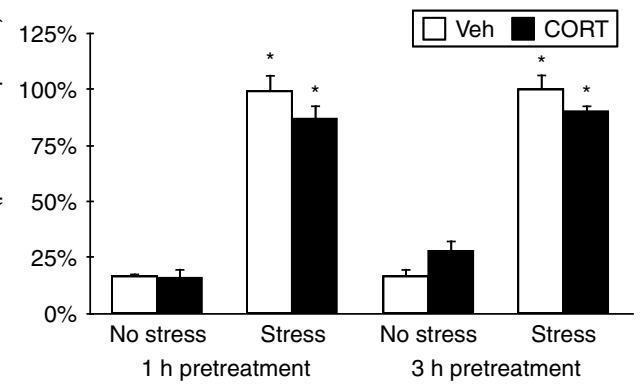

Intermediate lobe cfos mRNA CX-pretreated rats
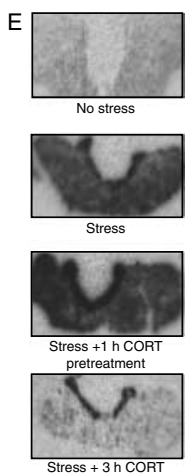
pretreatment

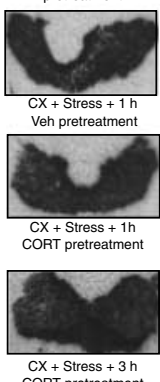

Figure 7 Effects of CORT pretreatment on basal and stress-induced pituitary anterior lobe and intermediate lobe $c$-fos mRNA levels of nonCX- or CX-pretreated rats. (A) In the absence of CX pretreatment, restraint produced a large increase in $c$-fos mRNA within the anterior pituitary. Pretreatment with CORT $3 \mathrm{~h}$, but not $1 \mathrm{~h}$, suppressed stress-induced anterior pituitary c-fos mRNA levels. (B) Systemic pretreatment with CX increased basal anterior pituitary $c$-fos mRNA levels and blocked the $3 \mathrm{~h}$ CORT pretreatment effect. (C) In the absence of CX pretreatment, restraint induced $c$-fos mRNA in the intermediate lobe of the pituitary, and CORT pretreatment had no effect. (D) CX pretreatment increased basal, but not stress-induced, $c$-fos mRNA in the intermediate lobe of the pituitary. Panel E shows representative autoradiographic images of the pituitaries from key comparison conditions depicted in panels A-D. Values are presented as a percentage of the mean value of the non-CX-pretreated stressed $3 \mathrm{~h}$ vehicle rats. ${ }^{*}$, significant stress effect within same drug condition and pretreatment time point $(P<0 \cdot 05, \mathrm{FLSD}) ;+$, significant CORT effect compared with vehicle-treated rats within the same pretreatment time and stress condition $(P<0 \cdot 05, \mathrm{FLSD})$; $\mathrm{R}$, significant difference between $\mathrm{CX}$-pretreated rats $(\mathrm{B}, \mathrm{D})$ compared with the corresponding non-CX-treated rats $(\mathrm{A}, \mathrm{C})(P<0 \cdot 05, \mathrm{FLSD})$

associated with the physiological consequences of long-term protein synthesis inhibition, as described by others (Davis \& Squire 1984, Rudy 2008). A key procedural difference between the study by Kovács et al. (1998) and our study was the duration of time after CX pretreatment when measurements were made, i.e. $30 \mathrm{~min}$ and $1.5-3.5 \mathrm{~h}$ respectively. The relatively long CX pretreatment time in our study $(1.5$ or $3.5 \mathrm{~h}$ ) probably allowed for the toxic effects of CX to fully manifest resulting in the marked HPA axis increases that we report. Plasma ACTH and gene expression in the PVN (crh hnRNA and c-fos mRNA) were much higher after protein synthesis inhibition than those observed after acute restraint. On the other hand, pomc and $c$-fos gene expression in the anterior pituitary exhibited only modest increases after protein synthesis inhibition, and there was no overall change in gene expression in the intermediate lobe. It appears then that the HPA axis-related excitatory effects present after protein synthesis inhibition were primarily due to systemic stress rather than generalized direct CX effects on cellular function and gene expression. Examination of CORT levels $1.5 \mathrm{~h}$ after protein synthesis inhibition also indicates that there was almost complete suppression of endogenous CORT production. Previous studies found that steroidogenesis is tightly coupled to de novo protein synthesis (Davis \& Garren 1968, Crivello \& Jefcoate 1978).

Although the apparent generalized systemic stress evident after CX treatment limits the extent to which we can draw firm conclusions about the protein synthesis-dependent nature of each of the CORT effects that we observed in non-CX-treated rats, it does provide some provisional information. Taken together, the results support that intermediate glucocorticoid negative feedback of HPA axis hormone secretion is dependent on glucocorticoid alteration of gene expression. It is not likely, however, that suppression of PVN crh and anterior pituitary pome gene expression accounts for the decreased stress-induced ACTH secretion present 1 or $3 \mathrm{~h}$ after CORT pretreatment (Watts 2005). Decreased ACTH content in corticotrophs is not observed until more than $6 \mathrm{~h}$ after continuous glucocorticoid treatment (Phillips \& Tashjian 1982, Shipston 1995). Consequently, the inhibitory effects of CORT on stress-induced HPA axis hormone secretion within the $3 \mathrm{~h}$ time frame appears to be 
due to induction of a gene and protein product that interferes with the coupling of cellular excitation with hormone secretion. Although $1 \mathrm{~h}$ is a fairly short interval of time to observe a protein synthesis-dependent functional effect of glucocorticoids, other studies have also reported a similar time frame for protein synthesis-dependent glucocorticoid inhibitory effects on corticotroph function in vitro (Dayanithi \& Antoni 1989, Woods et al. 1992, Clark \& Kemppainen 1994, Tierney et al. 2003). The fact that we observed additional protein synthesis-dependent inhibitory effects present at $3 \mathrm{~h}$ that were not present after $1 \mathrm{~h}$ suggests that there may be more than one target gene and cellular mechanism elicited by CORT over that period of time. There are a number of genes that are regulated by glucocorticoids, and some of them may participate in glucocorticoid negative feedback such as the calmodulin gene and various phosphatase and potassium-channel genes (Shipston \& Antoni 1992a,b, Kassel et al. 2001, Engelbrecht et al. 2003, Yamashita et al. 2009). Shipston et al. (1996) have provided some evidence in corticotrophs for rapid glucocorticoid suppression of stimulated ACTH secretion to depend on induction of a protein that leads to net activation of large conductance of $\mathrm{Ca}^{2+}$ and voltage-dependent $\mathrm{K}^{+}$ channels (BK channels), thereby reducing corticotroph membrane depolarization (Tian et al. 1998, 2001). However, the identity of such a glucocorticoid-induced protein remains elusive (Attarzadeh-Yazdi et al. 2008).

In summary, our study indicates that within the first $3 \mathrm{~h}$ after a phasic increase in CORT, CORT produces a protein synthesis-dependent inhibitory effect on subsequent HPA axis stress reactivity that appears to be exerted predominantly on the intrinsic anatomical elements of the HPA axis. In addition, over the course of $3 \mathrm{~h}$, CORT produces multiple molecular effects within the intrinsic HPA axis elements that have different onsets and durations of action. Some of those effects contribute directly to decreased stress-induced HPA axis hormone secretion during that $3 \mathrm{~h}$ period. Other effects, such as inhibition of $c r h$ and pomc gene expression, may have their primary impact on HPA axis function at later points in time.

\section{Declaration of interest}

The authors declare that there is no conflict of interest that could be perceived as prejudicing the impartiality of the research reported.

\section{Funding}

This study was supported by National Institute of Mental Health (NIH) grant MH75968.

\section{Acknowledgements}

We thank Erin Jarvis for help with the collection of tissue and Vanessa Thompson for help with the processing of samples and tissue.

\section{References}

Attarzadeh-Yazdi G, Shipston MJ \& Antoni FA 2008 Dex-ras1 and serumand glucocorticoid-inducible protein kinase 1: regulation of expression by dexamethasone in HEK293 cells. Neurochemical Research 33 609-613. (doi:10.1007/s11064-007-9516-5)

Autelitano DJ, Blum M \& Roberts JL 1989 Changes in rat pituitary nuclear and cytoplasmic pro-opiomelanocortin RNAs associated with adrenalectomy and glucocorticoid replacement. Molecular and Cellular Endocrinology 66 171-180. (doi:10.1016/0303-7207(89)90029-4)

Brattin WJ \& Portanova R 1977 Corticosterone induction of pituitary hyporesponsiveness to CRF: divergent effects of puromycin and cycloheximide. Molecular and Cellular Endocrinology 7 221-231. (doi:10. 1016/0303-7207(77)90054-5)

Bruehl H, Rueger M, Dziobek I, Sweat V, Tirsi A, Javier E, Arentoft A, Wolf OT \& Convit A 2007 Hypothalamic-pituitary-adrenal axis dysregulation and memory impairments in type 2 diabetes. Journal of Clinical Endocrinology and Metabolism 92 2439-2445. (doi:10.1210/jc.2006-2540)

Campeau S, Dolan D, Akil H \& Watson S 2002 c-fos mRNA induction in acute and chronic audiogenic stress: possible role of the orbitofrontal cortex in habituation. Stress 5 121-130. (doi:10.1080/10253890290027895)

Clark TP \& Kemppainen RJ 1994 Glucocorticoid negative feedback in sheep corticotrophs: a comparison with AtT-20 corticotroph tumor cells. American Journal of Physiology 267 R463-R469.

Crivello JF \& Jefcoate CR 1978 Mechanisms of corticotropin action in rat adrenal cells. I. The effects of inhibitors of protein synthesis and of microfilament formation on corticosterone synthesis. Biochimica et Biophysica Acta 542 315-329. (doi:10.1016/0304-4165(78)90027-2)

Dallman MF \& Yates FE 1969 Dynamic asymmetries in the corticosteroid feedback path and distribution-metabolism-binding elements of the adrenocortical system. Annals of the New York Academy of Sciences 156 696-721. (doi:10.1111/j.1749-6632.1969.tb14008.x)

Dallman MF, Akana SF, Cascio CS, Darlington DN, Jacobson L \& Levin N 1987 Regulation of ACTH secretion: variations on a theme of B. Recent Progress in Hormone Research 43 113-173.

Davis WW \& Garren LD 1968 On the mechanism of action of adrenocorticotropic hormone. The inhibitory site of cycloheximide in the pathway of steroid biosynthesis. Journal of Biological Chemistry $\mathbf{2 4 3}$ 5153-5157.

Davis HP \& Squire LR 1984 Protein synthesis and memory: a review. Psychological Bulletin 96 518-559. (doi:10.1037/0033-2909.96.3.518)

Dayanithi G \& Antoni F 1989 Rapid as well as delayed inhibitory effects of glucocorticoid hormones on pituitary adrenocorticotropic hormone release are mediated by type II glucocorticoid receptors and require newly synthesized messenger ribonucleic acid as well as protein. Endocrinology $\mathbf{1 2 5}$ 308-313. (doi:10.1210/endo-125-1-308)

Dostert A \& Heinzel T 2004 Negative glucocorticoid receptor response elements and their role in glucocorticoid action. Current Pharmaceutical Design 10 2807-2816. (doi:10.2174/1381612043383601)

Drouin J, Sun YL, Chamberland M, Gauthier Y, De Lean A, Nemer M \& Schmidt TJ 1993 Novel glucocorticoid receptor complex with DNA element of the hormone-repressed POMC gene. EMBOJournal 12 145-156.

Engelbrecht Y, de Wet H, Horsch K, Langeveldt CR, Hough FS \& Hulley PA 2003 Glucocorticoids induce rapid up-regulation of mitogen-activated protein kinase phosphatase-1 and dephosphorylation of extracellular signalregulated kinase and impair proliferation in human and mouse osteoblast cell lines. Endocrinology 144 412-422. (doi:10.1210/en.2002-220769)

Erdmann G, Berger S \& Schutz G 2008 Genetic dissection of glucocorticoid receptor function in the mouse brain. Journal of Neuroendocrinology 20 655-659. (doi:10.1111/j.1365-2826.2008.01717.x)

Feldman S \& Weidenfeld J 1993 The dorsal hippocampus modifies the negative feedback effect of glucocorticoids on the adrenocortical and median eminence CRF-41 responses to photic stimulation. Brain Research 614 227-232. (doi:10.1016/0006-8993(93)91039-U)

Freeman BC \& Yamamoto KR 2001 Continuous recycling: a mechanism for modulatory signal transduction. Trends in Biochemical Sciences 26 285-290. (doi:10.1016/S0968-0004(01)01834-5) 
Freeman ME, Kanyicska B, Lerant A \& Nagy G 2000 Prolactin: structure, function, and regulation of secretion. Physiological Reviews 80 1523-1631.

Galli U, Gaab J, Ettlin DA, Ruggia F, Ehlert U \& Palla S 2009 Enhanced negative feedback sensitivity of the hypothalamus-pituitary-adrenal axis in chronic myogenous facial pain. European Journal of Pain 13 600-605. (doi:10.1016/j.ejpain.2008.07.010)

Ginsberg AB, Campeau S, Day HE \& Spencer RL 2003 Acute glucocorticoid pretreatment suppresses stress-induced hypothalamic-pituitary-adrenal axis hormone secretion and expression of corticotropin-releasing hormone hnRNA but does not affect c-fos mRNA or fos protein expression in the paraventricular nucleus of the hypothalamus. Journal of Neuroendocrinology 15 1075-1083. (doi:10.1046/j.1365-2826.2003.01100.x)

Ginsberg AB, Frank MG, Francis AB, Rubin BA, O'Connor KA \& Spencer RL 2006 Specific and time-dependent effects of glucocorticoid receptor agonist RU28362 on stress-induced pro-opiomelanocortin hnRNA, c-fos mRNA and zif268 mRNA in the pituitary. Journal of Neuroendocrinology $\mathbf{1 8}$ 129-138. (doi:10.1111/j.1365-2826.2005.01396.x)

Girotti M, Pace TWW, Gaylord RI, Rubin BA, Herman JP \& Spencer RL 2006 Habituation to repeated restraint stress is associated with lack of stressinduced c-fos expression in primary sensory processing areas of the rat brain. Neuroscience 138 1067-1081. (doi:10.1016/j.neuroscience.2005.12.002)

Goudreau JL, Lindley SE, Lookingland KJ \& Moore KE 1992 Evidence that hypothalamic periventricular dopamine neurons innervate the intermediate lobe of the rat pituitary. Neuroendocrinology 56 100-105. (doi:10.1159/ 000126214)

Guardiola-Diaz HM, Kolinske JS, Gates LH \& Seasholtz AF 1996 Negative glucorticoid regulation of cyclic adenosine $3^{\prime}, 5^{\prime}$-monophosphatestimulated corticotropin-releasing hormone-reporter expression in AtT-20 cells. Molecular Endocrinology 10 317-329. (doi:10.1210/me.10.3.317)

Herman JP \& Mueller NK 2006 Role of the ventral subiculum in stress integration. Behavioural Brain Research 174 215-224. (doi:10.1016/j.bbr. 2006.05.035)

Herman J \& Spencer R 1998 Regulation of hippocampal glucocorticoid receptor gene transcription and protein expression in vivo. Journal of Neuroscience 18 7462-7473.

Herman JP, Schafer MK, Thompson RC \& Watson SJ 1992 Rapid regulation of corticotropin-releasing hormone gene transcription in vivo. Molecular Endocrinology 6 1061-1069. (doi:10.1210/me.6.7.1061)

Hinz B \& Hirschelmann R 2000 Rapid non-genomic feedback effects of glucocorticoids on CRF-induced ACTH secretion in rats. Pharmacentical Research 17 1273-1277. (doi:10.1023/A:1026499604848)

Imaki T, Xiao-Quan W, Shibasaki T, Yamada K, Harada S, Chikada N, Naruse M \& Demura H 1995 Stress-induced activation of neuronal activity and corticotropin-releasing factor gene expression in the paraventricular nucleus is modulated by glucocorticoids in rats. Journal of Clinical Investigation 96 231-238. (doi:10.1172/JCI118026)

Jacobson L \& Sapolsky R 1991 The role of the hippocampus in feedback regulation of the hypothalamic-pituitary-adrenal axis. Endocrine Reviews 12 118-134. (doi:10.1210/edrv-12-2-118)

Jerjes WK, Taylor NF, Wood PJ \& Cleare AJ 2007 Enhanced feedback sensitivity to prednisolone in chronic fatigue syndrome. Psychoneuroendocrinology 32 192-198. (doi:10.1016/j.psyneuen.2006.12.005)

Kassel O, Sancono A, Krätzschmar J, Kreft B, Stassen M \& Cato AC 2001 Glucocorticoids inhibit MAP kinase via increased expression and decreased degradation of MKP-1. EMBO Journal 20 7108-7116. (doi:10.1093/ emboj/20.24.7108)

Keller-Wood M \& Dallman M 1984 Corticosteroid inhibition of ACTH secretion. Endocrine Reviews 5 1-24. (doi:10.1210/edrv-5-1-1)

Kovács K 1998 c-Fos as a transcription factor: a stressful (re)view from a functional map. Neurochemistry International 33 287-297. (doi:10.1016/ S0197-0186(98)00023-0)

Kovács KJ \& Sawchenko PE 1996 Sequence of stress-induced alterations in indices of synaptic and transcriptional activation in parvocellular neurosecretory neurons. Journal of Neuroscience 16 262-273.

Kovács KJ, Arias C \& Sawchenko PE 1998 Protein synthesis blockade differentially affects the stress-induced transcriptional activation of neuropeptide genes in parvocellular neurosecretory neurons. Brain Research. Molecular Brain Research 54 85-91. (doi:10.1016/S0169-328X(97)00324-0)
Levy A 2002 Physiological implications of pituitary trophic activity. Journal of Endocrinology 174 147-155. (doi:10.1677/joe.0.1740147)

Lightman S, Wiles C, Atkinson H, Henley DE, Russell GM, Leendertz JA, McKenna MA, Spiga F, Wood SA \& Conway-Campbell BL 2008 The significance of glucocorticoid pulsatility. European Journal of Pharmacology 583 255-262. (doi:10.1016/j.ejphar.2007.11.073)

Lookingland KJ, Gunnet JW \& Moore KE 1991 Stress-induced secretion of alpha-melanocyte-stimulating hormone is accompanied by a decrease in the activity of tuberohypophysial dopaminergic neurons. Neuroendocrinology $\mathbf{5 3}$ 91-96. (doi:10.1159/000125703)

Mattsson C, Reynolds RM, Simonyte K, Olsson T \& Walker BR 2009 Combined receptor antagonist stimulation of the hypothalamic-pituitaryadrenal axis test identifies impaired negative feedback sensitivity to cortisol in obese men. Journal of Clinical Endocrinology and Metabolism 94 1347-1352. (doi:10.1210/jc.2008-2054)

McGimsey WC, Cidlowski JA, Stumpf WE \& Sar M 1991 Immunocytochemical localization of the glucocorticoid receptor in rat brain, pituitary, liver, and thymus with two new polyclonal antipeptide antibodies. Endocrinology 129 3064-3072. (doi:10.1210/endo-129-6-3064)

Meaney MJ, Viau V, Aitken DH \& Bhatnagar S 1988 Stress-induced occupancy and translocation of hippocampal glucocorticoid receptors. Brain Research 445 198-203. (doi:10.1016/0006-8993(88)91093-1)

Nestler E, Hyman S \& Malenka R 2001 Molecular Neuropharmacology. A foundation for clinical neuroscience. Edn 1, pp 130-133. New York, NY: The McGraw-Hill Companies, Inc.

Nicholson WE, Davis DR, Sherrell BJ \& Orth DN 1984 Rapid radioimmunoassay for corticotropin in unextracted human plasma. Clinical Chemistry $\mathbf{3 0}$ 259-265.

O'Connor K, Ginsberg A, Maksimova E, Wieseler Frank JL, Johnson JD, Spencer RL, Campeau S, Watkins LR \& Maier SF 2005 Stress-induced sensitization of the hypothalamic-pituitary-adrenal axis is associated with alterations of hypothalamic and pituitary gene expression. Neuroendocrinology 80 252-263. (doi:10.1159/000082876)

Ozawa H, Ito T, Ochiai I \& Kawata M 1999 Cellular localization and distribution of glucocorticoid receptor immunoreactivity and the expression of glucocorticoid receptor messenger RNA in rat pituitary gland. A combined double immunohistochemistry study and in situ hybridization histochemical analysis. Cell and Tissue Research 295 207-214. (doi:10.1007/s004410051226)

Pace TWW, Gaylord RI, Jarvis E, Girotti M \& Spencer RL 2009 Differential glucocorticoid effects on stress-induced gene expression in the paraventricular nucleus of the hypothalamus and ACTH secretion in the rat. Stress 12 400-411. (doi:10.1080/10253890802530730)

Pariante CM \& Miller AH 2001 Glucocorticoid receptors in major depression: relevance to pathophysiology and treatment. Biological Psychiatry 49 391-404. (doi:10.1016/S0006-3223(00)01088-X)

Paxinos G, Watson CR \& Emson PC 1980 AChE-stained horizontal sections of the rat brain in stereotaxic coordinates. Journal of Neuroscience Methods 3 129-149. (doi:10.1016/0165-0270(80)90021-7)

Phillips M \& Tashjian A 1982 Characterization of an early inhibitory effect of glucocorticoids on stimulated adrenocorticotropin and endorphin release from a clonal strain of mouse pituitary cells. Endocrinology 110 892-900. (doi:10.1210/endo-110-3-892)

Proulx-Ferland L, Labrie F, Dumont D, Cote J, Coy DH \& Sveiraf J 1982 Corticotropin-releasing factor stimulates secretion of melanocyte-stimulating hormone from the rat pituitary. Science 217 62-63. (doi:10.1126/ science.6283632)

Reichardt HM \& Schütz G 1998 Glucocorticoid signalling - multiple variations of a common theme. Molecular and Cellular Endocrinology 146 1-6. (doi:10.1016/S0303-7207(98)00208-1)

Reichardt H, Kaestner K, Tuckermann J, Kretz O, Wessely O, Bock R, Gass P, Schmid W, Herrlich P, Angel P et al. 1998a DNA binding of the glucocorticoid receptor is not essential for survival. Cell 93 531-541. (doi:10.1016/S0092-8674(00)81183-6)

Reichardt HM, Kaestner KH, Wessely O, Gass P, Schmid W \& Schütz G $1998 b$ Analysis of glucocorticoid signalling by gene targeting. Journal of Steroid Biochemistry and Molecular Biology 65 111-115. (doi:10.1016/S09600760(97)00181-7) 
Rudy J 2008 Is there a baby in the bathwater? Maybe: some methodological issues for the de novo protein synthesis hypothesis Neurobiology of Learning and Memory 89 219-224. (doi:10.1016/j.nlm.2007.08.014)

Shipston MJ 1995 Mechanism(s) of early glucocorticoid inhibition of adrenocorticotropin secretion from anterior pituitary corticotropes. Trends in Endocrinology and Metabolism 6 261-266. (doi:10.1016/1043-2760(95)00149-2)

Shipston M \& Antoni F 1992a Inactivation of early glucocorticoid feedback by corticotropin-releasing factor in vitro. Endocrinology 130 2213-2218. (doi:10.1210/en.130.4.2213)

Shipston MJ \& Antoni FA $1992 b$ Early glucocorticoid induction of calmodulin and its suppression by corticotropin-releasing factor in pituitary corticotrope tumor (AtT20) cells. Biochemical and Biophysical Research Communications 189 1382-1388. (doi:10.1016/0006-291X(92)90227-C)

Shipston MJ, Kelly JS \& Antoni FA 1996 Glucocorticoids block protein kinase A inhibition of calcium-activated potassium channels. Journal of Biological Chemistry 271 9197-9200. (doi:10.1074/jbc.271.16.9197)

Stavreva D, Wiench M, John S, Conway-Campbell B, McKenna M, Pooley J, Johnson T, Voss T, Lightman S \& Hager G 2009 Ultradian hormone stimulation induces glucocorticoid receptor-mediated pulses of gene transcription. Nature Cell Biology 11 1093-1102. (doi:10.1038/ncb1922)

Takigami S, Fujiwara K, Kikuchi M \& Yashiro T 2008 In vivo correlation between c-Fos expression and corticotroph stimulation by adrenocorticotrophic hormone secretagogues in rat anterior pituitary gland. Cell and Tissue Research 331 589-594. (doi:10.1007/s00441-007-0547-7)

Taylor AD, Cowell AM, Flower RJ \& Buckingham JC 1995 Dexamethasone suppresses the release of prolactin from the rat anterior pituitary gland by lipocortin 1 dependent and independent mechanisms. Neuroendocrinology 62 530-542. (doi:10.1159/000127044)

Tian L, Knaus HG \& Shipston MJ 1998 Glucocorticoid regulation of calcium-activated potassium channels mediated by serine/threonine protein phosphatase. Journal of Biological Chemistry 273 13531-13536. (doi:10.1074/jbc.273.22.13531)

Tian L, Hammond MS, Florance H, Antoni FA \& Shipston MJ 2001 Alternative splicing determines sensitivity of murine calcium-activated potassium channels to glucocorticoids. Journal of Physiology 537 57-68. (doi:10.1111/j.1469-7793.2001.0057k.x)

Tierney T, Christian HC, Morris JF, Solito E \& Buckingham JC 2003 Evidence from studies on co-cultures of TtT/GF and AtT20 cells that Annexin 1 acts as a paracrine or juxtacrine mediator of the early inhibitory effects of glucocorticoids on ACTH release. Journal of Neuroendocrinology $\mathbf{1 5}$ 1134-1143. (doi:10.1111/j.1365-2826.2003.01111.x)
Umemoto S, Kawai Y, Ueyama T \& Senba E 1997 Chronic glucocorticoid administration as well as repeated stress affects the subsequent acute immobilization stress-induced expression of immediate early genes but not that of NGFI-A. Neuroscience 80 763-773. (doi:10.1016/S0306-4522 (97)00050-X)

Watts A 2005 Glucocorticoid regulation of peptide genes in neuroendocrine CRH neurons: a complexity beyond negative feedback. Frontiers in Neuroendocrinology 26 109-130. (doi:10.1016/j.yfrne.2005.09.001)

Weiser M \& Spencer RL 2009 Regulation of stress-induced c-fos and corticotropin-releasing hormone gene expression in the hypothalamic paraventricular nucleus (PVN) by an acute PVN corticosterone microinjection. Society for Neuroscience Annual Meeting, Chicago.

Wingenfeld K, Wagner D, Schmidt I, Meinlschmidt G, Hellhammer DH \& Heim C 2007 The low-dose dexamethasone suppression test in fibromyalgia. Journal of Psychosomatic Research 62 85-91. (doi:10.1016/j. jpsychores.2006.06.006)

Wirtz PH, von Känel R, Emini L, Ruedisueli K, Groessbauer S, Maercker A \& Ehlert U 2007 Evidence for altered hypothalamus-pituitary-adrenal axis functioning in systemic hypertension: blunted cortisol response to awakening and lower negative feedback sensitivity. Psychoneuroendocrinology 32 430-436. (doi:10.1016/j.psyneuen.2007.02.006)

Woods MD, Shipston MJ, Mullens EL \& Antoni FA 1992 Pituitary corticotrope tumor (AtT20) cells as a model system for the study of early inhibition by glucocorticoids. Endocrinology 131 2873-2880. (doi:10.1210/ en.131.6.2873)

Yamashita M, Oki Y, Iino K, Hayashi C, Matsushita F, Faje A \& Nakamura H 2009 The role of ether-a-go-go-related gene K(+) channels in glucocorticoid inhibition of adrenocorticotropin release by rat pituitary cells. Regulatory Peptides 152 73-78. (doi:10.1016/j.regpep. 2008.09.002)

Yehuda R, Golier JA, Halligan SL, Meaney M \& Bierer LM 2004 The ACTH response to dexamethasone in PTSD. American Journal of Psychiatry 161 1397-1403. (doi:10.1176/appi.ajp.161.8.1397)

\section{Received in final form 16 December 2010 \\ Accepted 4 January 2011}

Made available online as an Accepted Preprint 4 January 2011 